\title{
GoogleTrends as a patient therapeutic education resource on extracorporeal life support: What do patients want to know?
}

\author{
Rene Aleman ${ }^{1}$, Sinal Patel ${ }^{1}$, Joel S. Frieder ${ }^{1}$, Jose Navia ${ }^{1}$, Cedric Sheffield ${ }^{1}$, and Nicolas \\ Brozzi $^{1}$ \\ ${ }^{1}$ Cleveland Clinic Florida
}

February 4, 2022

\begin{abstract}
Introduction Extracorporeal membrane oxygenation (ECMO) is implemented as a rescue therapy in COVID-19 related acute distress respiratory syndrome (ARDS) and refractory hypoxemia. Google trends (GT) is an ongoing-developing web-kit providing feedback on specific population's interests. This study uses GT to analyze the United States (US) general population interest in ECMO as COVD-19/ARDS salvage therapy. Methods GT was used to access data searched for the term ECMO and COVID-19. The gathered information included data from March 2020 through July 2021 within US territories. Search frequency, time intervals, sub-regions, frequent topics of interest, and related searches were analyzed. Data was reported as search frequency on means, and a value of 100 represented overall peak popularity. Results The number of Google searches related to the terms ECMO and COVID-19 has surged and sustained interest over time ever since the initial reports of COVID-19 in the US, from an initial mean of 34\% in March 2020 to a 100\% interest by April 2020, resulting in an up-to-date overall average of $40 \%$ interest. Over time West Virginia, Gainesville, and Houston, lead the frequency of searches in sub-region, metro and city areas, respectively. Top search terms by frequency include: ECMO machine, COVID ECMO, what is ECMO, ECMO treatment and $V V$ ECMO. Parallel to this, the related rising terms are: COVID ECMO, ECMO machine COVID, ECMO for COVID, ECMO machine coronavirus, and ECMO vs ventilator. Seemingly, medical-relevant websites fail to adequately address these for patient therapeutic education (PTE) purposes. Conclusions GT complements the understanding of interest in ECMO for COVID-19. When properly interpreted, the use of these trends can potentially improve on PTE and therapy awareness via specific medical relevant websites.
\end{abstract}

\section{Hosted file}

GT \&amp; ECMO_MANUSCRIPT.docx available at https://authorea.com/users/458877/articles/555328googletrends-as-a-patient-therapeutic-education-resource-on-extracorporeal-life-supportwhat-do-patients-want-to-know

\section{Hosted file}

GT \&amp; ECMO_TABLES \&amp; FIGURES.docx available at https://authorea.com/users/ 458877/articles/555328-googletrends-as-a-patient-therapeutic-education-resource-onextracorporeal-life-support-what-do-patients-want-to-know 